\title{
EJSBS
}

The European Journal of Social \&

Behavioural Science

ISSN: 2301-2218 (ONUNE)
OPEN ACCESS

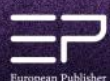

The European Journal of Social and Behavioural Sciences

EJSBS Volume XXIV, Issue III (eISSN: 2301-2218)

\section{VIRTUAL LEADERSHIP IN SMALL BUSINESSES DURING THE COVID-19 PANDEMIC: CHALLENGES AND POSSIBILITIES}

\author{
Roslind Xaviour Thambusamy ${ }^{\mathrm{a} *}$, Zafer Bekiroğulları ${ }^{\mathrm{b}}$ \\ ${ }^{a}$ INTI International College, Subang Jaya, Selangor, Malaysia \\ ${ }^{b}$ International Cognitive and Behavioural Psychotherapies Society, Trikomo, Cyprus
}

\begin{abstract}
The Covid19 pandemic has posed new challenges for leaders in both large and small businesses because of the new health measures that has forced people to work remotely to prevent the spread of the virus. This has led to organizations having to be managed virtually which brings with it its own set of challenges, especially for those who are unfamiliar with technology and used to face to face interaction. This is especially so for small businesses trying to remain afloat through resource constraints and a global economy in distress. Organizational leaders would need to have strategies in place to ensure that the productivity levels of employees remain as status quo or improve if that was possible. This research paper focuses on understanding the now very significant concept of virtual leadership in particular for small businesses by sieving through a focused literature review that covers this area of interest, including those that have suggested operating models that the leaders could utilize to invigorate their small businesses in order to subvert the projection by Bloomberg that $\$ 2.7$ trillion would be the ultimate payout in terms of economic losses as a result of this pandemic.
\end{abstract}

Keywords: Leadership, virtual leadership, small buisnesses, Covid19 pandemic

C) 2020 Published by European Publisher. www.europeanpublisher.com

${ }^{*}$ Corresponding author.

E-mail address: rxt56@live.com

doi: $10.15405 /$ ejsbs.281

This work is licensed under a Creative Commons Attribution-NonCommercial-NoDerivatives 4.0 International License. 
https://doi.org/10.15405/ejsbs.281

eISSN: 2301-2218 / Corresponding Author: Roslind Xaviour Thambusamy

Selection \& Peer-review under responsibility of the Editors

\section{Introduction}

\subsection{Small businesses and the effects of the COVID19 pandemic}

The current remarkably rough times caused by the global coronavirus outbreak have taken a serious toll on organizations, both public and private. These organizations have been forced to face the mother of all disruptions in the form of an invisible organism which reflects the adage that "size certainly does not matter" when it comes to creating challenges. This invisible organism called Covid19 virus has felled giant organizations, completely obliterating some in the areas of aviation and hotels, while bringing others to their knees. By now, it is no longer news that tourism and its related industries have been substantially affected especially small businesses like 2 - 3star hotels, F\&B outlets, laundries and so on that depended on tourists as a major source of income. Not just large organizations like airlines and big hotel chains, but also small businesses like tour operators, travel agents, car hire, have felt the blow. According to Mensah (2020), "all businesses and service providers along the tourism value chain including the farmer who supplies vegetables to a restaurant and a taxi driver who shuttles tourists from the airport to hotels are all affected" (n.p.). While large corporations may be more financially resilient in terms of how long they can remain closed for business, the same cannot be said for small businesses.

Before proceeding with the discussion, it is necessary to understand what constitutes a small business. According to McIntyre (2020), "Depending on your industry, a small business could be defined as business with a maximum of 250 employees or a maximum of 1,500 employees. They're privately owned corporations, partnerships, or sole proprietorships that have less revenue than larger businesses." However, the word "small" in business should not be underestimated as according to the same source, the cornerstone of the US economy are 28 million small businesses that comprise $99.7 \%$ of all U.S. firms, which means that "small business is big for the United States' economy" (n.p.). This scenario is reflected in the global economy as "small-and medium-sized enterprises (SMEs) represent over 90 per cent of the business population, $60-70 \%$ of employment and $55 \%$ of GDP in developed economies. SMEs therefore do not just significantly contribute to the economy - they ARE the economy" (Arnold, 2019, n.p.). Hence, the notion that "small" is insignificant is definitely out of order here, especially in terms of small businesses' role as an employer and a contributor to economic growth. In view of this, the authors believe that an analysis of studies into how these small businesses have and will continue to survive under the onslaught of the current pandemic is timely and useful to organizational leaders looking for ways to keep their organizations afloat. The gravity of this issue is underlined by the findings of a study undertaken by Bartik et al. (2020) which sampled 5,800 small businesses in the US. According to their study, "many 
https://doi.org/10.15405/ejsbs.281

eISSN: 2301-2218 / Corresponding Author: Roslind Xaviour Thambusamy

Selection \& Peer-review under responsibility of the Editors

small businesses are financially fragile: The median business with more than $\$ 10,000$ in monthly expenses had only about 2 wk of cash on hand at the time of the survey" (n.p.). Hence, one can see that, unless small business leaders find ways to stay in financially viable, this pandemic could be the end of the road not only for them but for entire economies.

In view of this, the most serious challenge for small businesses has been to the leadership of these organizations trying to keep their entities financially afloat while ensuring that their employees are heeding the health measures put in place (Jarrell \& Likowski, 2020). During the past few months of total lockdown in many countries, business leaders have been leading their teams virtually as they work across distance, different time zones, and organizational boundaries. While large corporations may have the resources to equip their employees to enable them to work remotely effectively, this could be difficult for small businesses. Working remotely necessitates the use of technology like computers and internet connectivity, which may not be available to employees of small businesses. Small businesses that operate in rural or isolated areas with limited or even no connectivity obviously negates the whole premise of virtual interaction.

So, in the first place, virtual leadership requires the leaders of these businesses to ensure that their employees have an adequate remote working environment for them to be productive. Most small businesses are already struggling with the receding global economy that is extensively affecting their operations (Bartik et al., 2020; Ferry, 2020). On top of this, they have to contend with the added challenge of ensuring that employees' productivity levels remain unaffected.

\subsection{Virtual Leadership and the COVID19 pandemic}

In his focal article entitled Virtual Leadership: An Important Leadership Context, Schmidt (2014) elucidates the idea of the context of leadership and why it has become increasingly prevalent in today's organizations. This context can influence "who is seen as a leader, how effective a leader is perceived to be, and how effective a leader actually is" (Schmidt, 2014, p. 183). He goes on to add that "The virtual team context is a context that may have strong impact on "who leads, why they lead, and how they lead" (Lord \& Dinh, 2014, as cited in Schmidt, 2014, p.183). A virtual team is one that "has members who potentially span different organizations, time zones, geographic locations, and cultures with technology enabling communication and coordination between members" (Huang et al., 2010; Johnson, 2010). Schmidt (2014) cites a study by MCIWorldcom (2001) which found that for companies with 500 or more employees, which fall in the category of a small business, more than $60 \%$ of employees reported already engaging on virtual teams, while another study projected that for 
https://doi.org/10.15405/ejsbs.281

eISSN: 2301-2218 / Corresponding Author: Roslind Xaviour Thambusamy

Selection \& Peer-review under responsibility of the Editors

companies with over 10,000 employees, $80 \%$ would be engaging virtually. Hence, virtual teams are no longer the exception but the norm in many businesses even prior to the pandemic, particularly those with international reach. Despite this, in terms of the extensiveness and depth of research into virtual teams, Schmidt opines that while current research base has allowed for an understanding into virtual leadership, it nevertheless does not reflect the burgeoning presence of virtual teams in organizations and, by default, the importance of virtual leadership (p. 182).

In light of the current pandemic and the concurrent health restrictions, effective virtual leadership can be seen as a lifebuoy for struggling businesses. Good virtual leaders can resuscitate dying businesses and stall their imminent collapse. The argument for virtual leadership to keep organizations operational is especially timely in helping leaders deal with the challenges of running organizations remotely.

\section{Purpose of the Study}

This paper intends to examine how, in the face of the coronavirus pandemic, small businesses can keep operations running by relying on virtual leadership to guide their employees. Until recently, the idea of virtual leadership especially for small businesses did not figure significantly as an important research topic. However, the challenges of keeping businesses operational within the constraints of the pandemic have thrust the concept of virtual leadership into the research limelight. Through an integrative review of current opinions and study findings, this paper attempts to contribute to the growing body of information in this now crucial area.

\section{Research Question}

This paper studies the question of how virtual leadership can be harnessed to run small businesses effectively and some challenges accompanied by possible solutions that can contribute to the successful deployment of virtual leadership in such businesses.

\section{Research Methodology}

This literature review encompasses the research of scholars who have discussed the concept of virtual leadership and its growing importance in the current business environment, specifically during the coronavirus pandemic. Also, the references to the selected materials were utilized in locating more research articles related to the topic of discussion. A thorough reading of various materials on the impact of the pandemic of small businesses generated the research questions which provided the keywords and phrases used to identify relevant sources 
https://doi.org/10.15405/ejsbs.281

eISSN: 2301-2218 / Corresponding Author: Roslind Xaviour Thambusamy

Selection \& Peer-review under responsibility of the Editors

from online databases such as Google Scholar and Ebscohost as well as search engines on the internet. The phrases used to delimit the literature review included 'virtual leadership and the pandemic,' 'COVID-19 and leadership', 'management in COVID-19' and 'small businesses and virtual leadership'. A range of materials, including web pages, journal articles, and opinion pieces were shortlisted as relevant to the research. The cut off criteria used to narrow the scope to the topic at hand was determined on the basis of the credibility of the publisher, the currency of publication, and the relationship to the identifying phrases and words. The research design was entirely qualitative in nature comprising an integrative review approach where a comprehensive document analysis of the materials was undertaken specifically to consider their contribution to this discussion. The collected findings were analyzed, interpreted and synthesized to answer the research questions driving this study. The prevalent themes that emerged from the analysis of the materials were then arranged in a cohesive manner to be presented in the discussion section.

\section{Findings and Discussion}

The coronavirus pandemic, as a global phenomenon, has taken a heavy toll on lives and livelihoods, rendering organizations, especially small businesses, helpless. While most organizational leaders are, in theory, aware of disruptions and changes that may upset standard organizational procedures, a significant number would have never, in their wildest dreams, imagined the scenario created by this pandemic. Complete lockdowns lasting for months and no non-essential movement permitted by many of the world's governments in a concerted effort to flatten the curve and prevent the spread of the virus, has left most business leaders scrambling for plan B to keep their organizations afloat.

While a number would have understood the extensiveness of challenges confronting them, not many were ready for a problem that would hinder them from meeting with essential stakeholders required to stay operational. Obviously at this time, technology came to the rescue to facilitate certain leadership processes via virtual platforms (Gottfridsson, 2010). However, controlling all employees across distinct times and locations can be difficult, especially with resource constraints in ensuring everyone has an excellent remote working environment. Notably, Saltman (2020) pointed out this should be a growth opportunity for the small business. A significant correlation exists between a virtual leader's keen emotional intelligence and the overall work engagement with his or her members to the success of the virtual environment (Sebastian \& Hess, 2019). A successful leader will be one that is able to balance 
https://doi.org/10.15405/ejsbs.281

eISSN: 2301-2218 / Corresponding Author: Roslind Xaviour Thambusamy

Selection \& Peer-review under responsibility of the Editors

the monitoring of work output and giving the virtual members an adequate autonomy to conduct themselves remotely.

Through technology, this virtual team can communicate and coordinate with other members to achieve organizational objectives (Huang et al., 2010). Hoch and Kozlowski (2014) claim that while significant work has been done to ensure virtual teams actually excel, the same zeal is lagging for virtual leadership to support employees' productivity. While there are still uncertainties on how leaders should conduct themselves to achieve a successful follower performance by the employers; a streamlined communication and enhanced personal connections between the parties have predicted a more significant positive impact within the virtual environment (Samartinho et al., 2014).

Holloway (2013) has indicated that most scholarly researchers focus on the operations of large companies and their needs. There is limited research on small businesses and their leadership, yet in most aspects, what works for the large enterprises may not work for the small ones (Ekanem, 2010). Unlike major corporations, small do not have large cash reserves, and because of the nature of small businesses, their leaders may often lack the prerequisite knowledge to achieve success in the face of substantial challenges. Most small businesses operate on a small scale in terms of stakeholders and output; but since these organizations have a considerable impact on the economy and the environments they operate in, they should receive the necessary support to ensure they have skilled leaders who are able to improvise sustainability practices for long-term growth. This is where governmental aid would be useful in terms of providing training for small business leaders to expose them to appropriate leadership strategies during this challenging time.

Despite the bleak forecast, Argenti (2020) has pointed out that the coronavirus pandemic had not doomed these organizations. Indeed, this pandemic has forced small and large business leaders to accept the fact that virtual leadership is here to stay. However, there are some steps that the organization needs to take to ensure continuous operations. The measures include creating a team for centralized communication, constant communication with employees and customers, reassuring the shareholders, and enhanced proactivity within the communities in which they operate. These steps will ensure contact is maintained with essential stakeholders who are integral to the success of any business organization. According to Danneels (2011), the importance of virtual leadership lies in the ability of the leaders to spearhead the dynamic capability of the organization in the face of challenges. Eisenhardt and Martin (2000) show that the businesses that continue to strive in the face of intensive challenges are those that can adapt and renew their resources to survive. This should be the 
https://doi.org/10.15405/ejsbs.281

eISSN: 2301-2218 / Corresponding Author: Roslind Xaviour Thambusamy

Selection \& Peer-review under responsibility of the Editors

case for small businesses and their leaders which, despite their limited resources, have to find ways to turn their limitations around to their advantage.

As Husbands (2020) indicates, this pandemic may actually accelerate much-needed development in small businesses. It is now the time for the leaders of small businesses, even mom-and-pop stores, to venture into adopting technology to enhance their business practices. For instance, a typical mom and pop store like a family owned bakery would need to utilize social media platforms or dedicated apps to interact with their customers in terms of daily specials and offers to maintain or generate sales, liaise with food delivery services, and payments. The entire transaction chain would now have to shift from face to face to a virtual environment. Obviously, the essence of certain small businesses like the mom and pop stores pride themselves on the "personal touch" style of doing business with much emphasis on the body language cues, tone of voice, and other familiarity building mechanisms inherent in face to face interaction. They may be uncomfortable with and reject virtual communication which is devoid of the face to face familiarity. However, to be practical, the leaders of such operations have to familiarize themselves very quickly to the new normal of doing business or risk becoming 'collateral damage' of the pandemic. Online social media, with its myriad functions, is an option that can still incorporate the personal touch style, though at a distance. Indeed, social media is one area that potentially can have a huge impact on how virtual leaders communicate with a team and how team members communicate with each other (Schmidt, 2014) as well as how they interact with their stakeholders.

Effective working models of virtual leadership need to ensure that they factor in continued social distancing and other pandemic related restrictions, keep track of and alleviate financial and other resource emergencies, initiate and keep interaction channels open between leaders and staff as well as between staff teams, and stakeholders, devise new work and engagement patterns to effectively lead at this time. To achieve a balance between the required forms of engagement and working, the virtual leaders have to devise strategic methods that will overcome the challenges of this pandemic (Macauley, 2020). In line with this, Raffoni (2020) has identified a number of challenges that virtual leaders, especially those who are not digital natives or millennials, may face and possible strategies that leaders can use to optimize their virtual leadership.

\subsection{Challenges to virtual leadership}

- Virtual interaction takes you out of your comfort zone, especially for those who are not as familiar with technology as the digital native and millennial generation, making it harder for some to "open up, connect, trust, and communicate with" (n.p) others 
virtually. The challenge is trying to maintain the same levels of authenticity as is enjoyed with face to face interaction. Authenticity, as in the personal touch style of business interaction is, for some small business leaders, an integral part of their leadership style and these leaders may not react and respond well in the virtual environment. This leads to the second challenge where;

- virtual interaction is seen to affect interpersonal dynamics. The virtual platform by its very nature does not allow for the same physical "closeness" that is evident in face to face interactions, where "the appropriate affect, tone, pacing, and facial expressions that we rely on for effective communication in person are more difficult to give and receive virtually, especially in group settings" (n.p.). Obviously then, when communicating over a video or some other online media, there is always the possibility that;

- people can be distracted. Ensuring your team is actually engaged throughout the meeting is almost impossible as "virtual meetings often come with a plethora of new distractions that you have little control over". Unless, you are interacting with the team via video call, you can't actually tell if team members are engaged or slacking off. This means that;

- $\quad$ equipping yourself with new skills is unavoidable. From learning technological skills like how to operate virtual platforms to strengthening facilitation skills, restrategizing work flows and teams, and dealing with issues virtually but in real time are skills that virtual leaders have to amass and optimize to ensure the continual survival of their businesses.

These challenges can be successfully overcome with some strategic rethinking in personal leadership styles, like reassessing;

- interactional and communication strategies. In lieu of face to face meetings and communication, virtual leaders need to seriously consider their "purpose, audience, and the context of the exchange" by listing their "objectives, agenda, and the amount of time you want to spend on each item" (n.p). To make up for the absence of face to face nonverbal feedback, virtual leaders need to increase engagement time and opportunities for the team members in order to receive their feedback. Additionally, more encouraging discourse needs to be used to draw out those team members who may be reticent in the virtual interactional environment which may be unfamiliar to them. The onus is on the leaders to initiate, encourage and sustain discourse on the virtual platform. While keeping to the agenda, keeping the communication channel open to support the dynamic 
nature of team discourse, is essential and should be supplemented with continual checks with team members to ensure that everyone is engaged. This can be done by calling out members every so often to answer questions or to provide comments on ideas being discussed. Without the intermittent prod, it is very easy to become invisible in the virtual environment. The "strong, silent man/woman of a few words" leadership style is not going to work well in the virtual environment.

- communications protocols. How things were done is the face to face environment may not apply in the virtual one like the frequency and duration of meetings. For instance, a face to face meeting that lasted an hour may not necessarily last as long in the virtual environment simply because the virtual environment does not really encourage digressions or side conversations amongst team members. Another consideration is the quality of the interaction offered by the various online media available. Would a voice only meeting suffice or is video interaction required? Who and what context would require particular modes of virtual communication? How can urgency be transmitted over a virtual platform? As a virtual leader, these and other questions need to be considered either alone or with the strategy team and revised protocols implemented to optimize communication. A note of caution needs to be sounded here as revisions, when needed, should be implemented with as little fuss as possible as this is the first time most small business leaders may be engaging in virtual leadership so strategies failing should be expected and dealt with minimal repercussions to team morale.

- roles and responsibilities. The virtual environment may not be everyone's favoured modus operandi for communication which will affect the affected members' productivity. Virtual leaders need to be extra sensitive and accommodative as far as possible to their employees' working and communication preferences. While the younger generation being digital natives were weaned on technology and have no issues communicating via social media platforms, the older generation may balk at communicating important and personal views via virtual platforms. Additionally, they may not be familiar with the basic operational functions of certain online platforms. The leader needs to be cognizant of these challenges and identify those who may need training or help in how to cope with working efficiently in the virtual environment. Roles and responsibilities may have to reassessed in view of the new skills needed to operate effectively as a virtual worker. However, all this must be done in an atmosphere of respect and tact as sensitivities would be stretched at this time, compounded by the fear that their livelihood may be affected by the revamping of organizational operations. 
The virtual leader must, thus tread with extreme caution in terms of how role reassessment and reassignments are worded.

While occupied with the nitty-gritties of day to day organizational operations, it is easy to overlook the big picture goals of the business. It essential for virtual leaders to not allow the operational details swamp the need for them to keep focused on the ultimate aims of the organization which is to stay economically and financially relevant and productive in whatever area of economic enterprise it is engaged in. Leaders need to think about not just surviving but thriving in this scenario as challenges always open new doors of opportunities as leaders would be "forced" to reconsider previous priorities and recast them to fit the new normal. Virtual leadership in this time of remote working and social distancing can actually be a boon as leaders would have more time to mull over big picture issues.

These are of course, only some strategies that virtual leaders of small businesses may find useful to lead their organizations safely through the tumultuous repercussions of the pandemic. There would be others that may be just as useful. What is important here is to harness whatever strategies are available and appropriate to ensure that the organization is able to continue operating while remaining financially viable.

\section{Conclusion}

It has come to the point now where the question for small businesses' survival is no longer whether to go virtual or not but how to optimize virtual leadership to get the best of the employees and how to deliver the best service or products to the customers. At a time when employees are looking to their leaders to lead the way, whatever option is available must be embraced and challenges overcome to ensure that livelihoods are safe.

The coronavirus pandemic that has toppled many major organizations and small businesses, is to a large extent, the fault of the leadership that was not agile enough to respond in a timely manner to the challenges. Leaders' capacity to lead the organizations virtually in the face of limited resources and a receding global economy will determine how far the business survives through the pandemic. As Abrahamsson and Ollander Axelsson (2020) indicate, the small business that will survive in this pandemic will be one that realizes the value and utility of harnessing the virtual environment efficiently through appropriate virtual leadership.

\section{Acknowledgements}

The author(s) declare that there is no conflict of interest. 
https://doi.org/10.15405/ejsbs.281

eISSN: 2301-2218 / Corresponding Author: Roslind Xaviour Thambusamy

Selection \& Peer-review under responsibility of the Editors

\section{References}

Abrahamsson, E., \& Ollander Axelsson, J. (2020). Virtual leadership: Moving teams online during the covid-19 crisis [Unpublished Master's Thesis]. Linnaeus University, School of Business and Economics, Department of Organisation and Entrepreneurship, Sweden. http://www.diva-portal.org/smash/record.jsf? pid= diva2\%3A1434042\&dswid=-7911

Argenti, P. A. (2020, March 13). Communicating through the coronavirus crisis. Harvard Business Review. https://hbr.org/2020/03/communicating-through-the-coronaviruscrisis

Arnold, C. (2019, June 26). The Foundation for Economies Worldwide is small Business. International Federation of Accountants. https://www.ifac.org/knowledgegateway/contributing-global-economy/discussion/foundation-economies-worldwidesmall-business-0

Bartik, A. W., Bertrand, M., Cullen, Z., Glaeser, E. L., Luca, M., \& Stanton, C. (2020). The Impact of COVID 19 on small business outcomes and expectations. PNAS July 28, 117(30) 17656-17666. https://doi.org/10.1073/pnas.2006991117

Danneels, E. (2011). Trying to become a different type of company: Dynamic capability at Smith Corona. Strategic Management Journal, 32(1), 1-31. https://doi.org/10.1002/smj.863

Eisenhardt, K. M., \& Martin, J. A. (2000). Dynamic capabilities. Strat. Mgmt. J., 21, 1105 1121. https://doi.org/10.1002/1097-0266(200010/11)21:10/11<1105::AIDSMJ133>3.0.CO;2-E

Ekanem, I. (2010). Liquidity management in small firms: A learning perspective. Journal of Small Business and Enterprise Development, 17(1), 123-138. https://doi.org/10.1108/14626001011019161

Ferry, K. (2020). The Covid-19 Leadership Guide: Strategies for managing through the crisis. https://www.kornferry.com/content/dam/kornferry/special-projectimages/coronavirus/docs/KF_Leadership_Playbook_Global_FINAL.pdf

Gottfridsson, P. (2010). Development of personalized services in small business: An iterative learning process. Managing Service Quality, 20, 388-400. https://doi.org/10.1108/0960452 1011057504

Hoch, J. E., \& Kozlowski, S. W. (2014). Leading virtual teams: Hierarchical leadership, structural supports, and shared team leadership. Journal of applied psychology, 99(3), 390. https://doi.org/10.1037/a0030264

Holloway, D. E. (2013). Understanding leadership in small business from the perspectives of practitioners. Walden Dissertations and Doctoral Studies. 479. https://scholarworks.waldenu.edu/dissertations/479

Huang, R., Kahai, S., \& Jestice, R. (2010). The contingent effects of leadership on team collaboration in virtual teams. Computers in Human Behavior, 26(5), 1098-1110. https://doi.org/10.1016/j.chb.2010.03.014

Husbands, C. (2020). Leading, learning, and lockdown: first thoughts on lessons for leadership from the coronavirus crisis. Sheffield Hallam University

Jarrell, B. E., \& Likowski, A. (2020). Virtual Face to Face with Dr. Bruce Jarrell: Leadership in Crisis. https://youtu.be/uBNOrYRZ6OY 
Johnson, K. (2010). Virtual leadership: Required Competencies for Effective Leaders (CAHRS White Paper), Ithaca, NY: Cornell University, ILR School, Centre for Advanced Human Resource Studies

Macauley, A. (2020, April 10). How COVID-19 Could Shift the College Business Model: 'It's Hard to Go Back', Forbes. https://www.forbes.com/sites/alisonmccauley/2020/04/09/how-covid19-could-shiftthe-college-business-model/

McIntyre, G. (2020). What is the SBA's Definition of Small Businesses (And Why)? $\mathrm{https}$ ://www.fundera.com/blog/sba-definition-of-small-business

Mensah, I. (2020, May 13). Unpacking the Impacts of COVID19on Tourism and Repackaging the Hotel Service. https://www.hospitalitynet.org/opinion/4098657.html

Raffoni, M. (2020, May 1). 5 Questions That (Newly) Virtual Leaders Should Ask Themselves. Harvard Business Review. https://hbr.org/2020/05/5-questions-that-newly-virtualleaders-should-ask-themselves

Saltman, D. C. (2020). Is COVID-19 an opportunity to improve virtual leadership? Aust J Gen Pract, 49(12). https://doi.org/10.31128. AJGP-COVID-12

Samartinho, J., da Silva, P. P., \& Faria, J. (2014). Good practices in virtual leadership-thee3 cs rule (communication, trust, and coordination). ECKM, 2014

Schmidt, G. B. (2014). Virtual leadership: An important leadership context. Industrial and Organizational Psychology, 7(2), 182-187. https://doi.org/10.1111/iops.12129

Sebastian, K., \& Hess, J. (2019). Leader emotional intelligence and work engagement in virtual teams within a healthcare service setting: A quantitative study. Oklahoma State Medical Proceedings, 1(4). http://www.okstatemedicalproceedings.com/index.php/OSMP/ article/view/81 